Vol. 1 No. 2, Juni 2021, hlm. 161 - 166

DOI: https://doi.org/10.33330/jutsi.v2i1.1163

Available online at http://jurnal.stmikroyal.ac.id/index.php/jutsi

\title{
PENERAPAN DATA MINING UNTUK KLASIFIKASI PRODUK MERK BATA MENGGUNAKAN ALGORITMA K-MEANS
}

\author{
Hernita Samosir ${ }^{1}$, Muhammad Amin ${ }^{2}$, Indra Ramadona Harahap ${ }^{3}$ \\ ${ }^{1}$ Mahasiswa Prodi Sistem Informasi, STMIK Royal \\ ${ }^{2}$ Prodi Sistem Komputer,STMIK Royal \\ ${ }^{3}$ Prodi Manajemen Informatika, STMIK Royal \\ *email : stmikroyal13@gmail.com
}

\begin{abstract}
Tanjungbalai Bata Store is a store that is engaged in the business of selling products and every day processes purchase data, sales data and transaction data. Transaction data is the result of sales that can be obtained so that store management knows the strategies that will be carried out to increase sales results. As for consumers who make transactions at stores for a separate reason, especially because of the completeness and many models that can be obtained from the Tanjungbalai brick shop, another reason is that the Tanjungbalai Brick Shop can provide a sense of comfort and peace in addition and the cleanliness seen from the store. There are many types of products sold at the Tanjungbalai Brick Shop. However, Tanjungbalai Brick Shop cannot classify products that are selling well and those that are not selling well. So that the difficulties experienced are the frequent shortage of stock of products that sell well because sales are high and the accumulation of products that are not selling well in the warehouse because the sellers are low. Based on the problems above, data mining is needed to classify which products are in demand and which are not. Data mining and k-means methods can help in this research combined with the PHP programming language and MySQL database.
\end{abstract}

Keywords:Data Mining; Product Classification; K-Means Algorithm.

\begin{abstract}
Abstrak:Toko Bata Tanjungbalai adalah toko yang bergerak di bidang bisnis penjulalan produk dan setiap harinya melalukan proses data pembelian, data penjualan maupun data transaksi. Data transaksi merupakan hasil penjualan yang di dapat agar manajemen toko mengetahui strategi yang akan di lakukan untuk meningkatkan hasil penjualan. Adapun konsumen yang melakukan transaksi di toko memiliki alas an tersendiri ataupun di karenakan kelengkapan dan banyak model yang bisa di dapatkan dari toko bata tanjungbalai, alasan yang lain adalah Toko Bata Tanjungbalai dapat memberikan rasa nyamandan tentram di tambah lagi keramahan dan kebersihan yang di lihat dari toko tersebut. Ada banyak jenis produk yang terjual di Toko Bata Tanjungbalai, namun toko bata Tanjungbalai tidaklah mampu dalam membagikan kelompok produk tersebut masuk kategori laris dan tidak laris. Sehingga kesulitan yang dialami yaitu seringnya kekurangan stok produk yang laku karena penjualannya tinggi dan menumpuknya produk yang tidak laris di gudang karena penjualnnya rendah. Berdasarkan permasalahan di atas maka dibutuhkan data mining untuk mengelompokkan produk mana saja yang laris dan tidak. Data mining dan metode k-meansdapat membantu dalam penelitian ini dipadukan dengan pemrograman PHP dan MySQL.
\end{abstract}

Kata Kunci :Data Mining; Klasifikasi Produk; Algoritma K-Means. 
Vol. 1 No. 2, Juni 2021, hlm. 161 - 166

DOI: https://doi.org/10.33330/jutsi.v2i1.1163

Available online at http://jurnal.stmikroyal.ac.id/index.php/jutsi

\section{PENDAHULUAN}

Pertumbuhan ekonomi saat ini begitu pesat menjadikan persaingan yang signifikan dalam melakukan proses penjualan produk. Terlihat dari banyak para pelaku bisnis yang harus menerapkan strategi penjulaan dan dapat menarik minat para konsumen, tidak terlepas dari penelitian yang dilakukan di toko bata tanjungbalai yang bergerak dalam bidang penjualan produk. Pelaku bisnis harus pandai melihat situasi pasar agar barang dagangan laris terjual, oleh karena itu di bangunlah suatu sistem untuk menunjang agar penjualan dapat tercapai dengan baik.

Data transaksi penjualan merupakan tolak ukur dalam menentukan pendapatan atau hasil dari penjualan. Oleh karena itu pondasi dari bisnis ini adalah strategi yang akan dilakukan dan pandai membaca pasar, agar produk yang di pasarkan laris terjual. Jika saja gagal dalam proses ini akan berdampak kedalam kerugian dan bahkan kebangkrutan.

Untuk mengatasi permasalahan di atas, maka dibutuhkan data mining untuk mengelompokkan produk mana saja yang laku dan tidak. Data mining merupakan analisa terhadap data untuk menemukan hubungan yang jelas serta menyimpulkannya yang belum diketahui sebelumnya dengan cara terkini dipahami dan berguna bagi pemilik data tersebut [1].

Metode yang digunakan dalam penelitian ini adalah algoritma $K$-Means merupakan salah satu metode dalam data mining. Di mana pada metode ini dilakukan pengelompokan data (clustering) dengan sistem partisi dan pemodelannya tanpa supervisi. Dalam metode ini pengelompokan data dilakukan menjadi beberapa kelompok, dan tiap kelompok memiliki kesamaan karakteristik dan memiliki karakteristik dengan kelompok lainnya [2].

Alasan penggunaan algoritma $K$-Means di antaranya ialah karena algoritma ini memiliki ketelitian yang cukup tinggi terhadap ukuran objek, sehingga algoritma ini relatif lebih terukur dan efisien untuk pengolahan objek dalam jumlah besar. Selain itu algoritma K-Means ini tidak terpengaruh oleh urutan objek [3]. Hierarchical clustering adalah suatumetode pengelompokan data yang dimulai dengan mengelompokkan dua atau lebih objek yang memiliki kesamaan paling dekat. Kemudian proses diteruskan ke objek lain yang memiliki kedekatan kedua. Berbeda dengan metode hierarchical clustering, metode non hierarchical clustering justru dimulai dengan menentukan terlebih dahulu jumlah cluster yang diinginkan (dua cluster, tiga cluster, atau lain sebagainya) [4].

\section{METODE}

Penelitian ini menggunakan metode kuantitatif dengan banyak mengolah data berupa angka yang akan di hitung menggunakan rumus, sehingga memperoleh hasil berdasarkan perhitungan dengan rumus tersebut. Tujuan metode penelitian ini adalah untuk mendeskripsikan objek yang diteliti yaitu klasifikasi produk merk Bata pada Toko Bata Tanjungbalai menggunakan algoritma K-Means. 
Vol. 1 No. 2, Juni 2021, hlm. 161 - 166

DOI: https://doi.org/10.33330/jutsi.v2i1.1163

Available online at http://jurnal.stmikroyal.ac.id/index.php/jutsi

\section{HASIL DAN PEMBAHASAN}

Setelah melalui tahap uji coba sistem, penerapan data mining untuk klasifikasi produk merk bata menggunakan algoritma K-Means di Toko Bata Tanjungbalai dikembangkan dengan pemrograman $P H P$ dan $M Y S Q L$ yang disimpan pada server yang dibangun, sehingga menghasilkan sistem yang diperlukan dalam proses pengklasifikasian produk oleh admin. Adapun tampilan awal dari sistem :

\section{Tampilan Login}

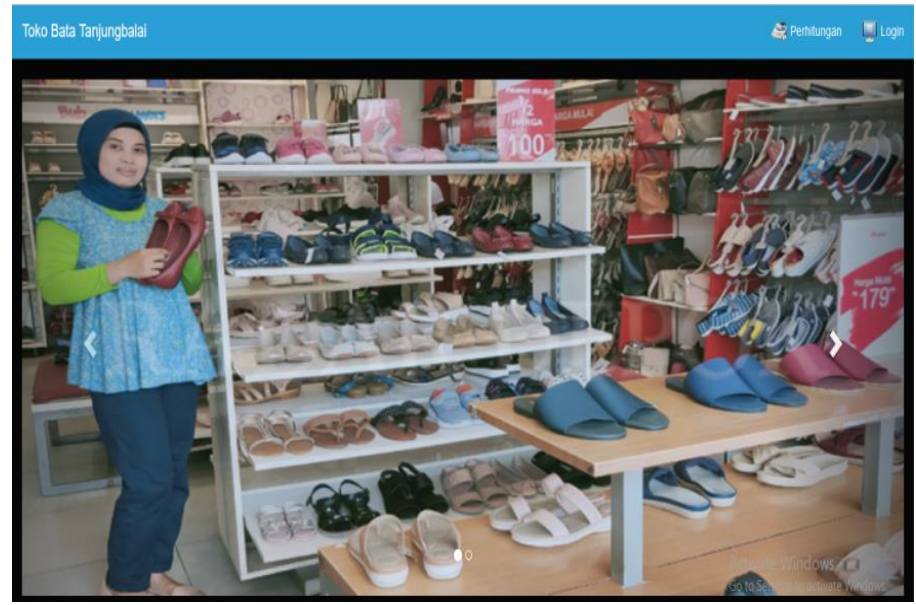

Gambar 1. Tampilan Login

\section{Tampilan Menu Utama}

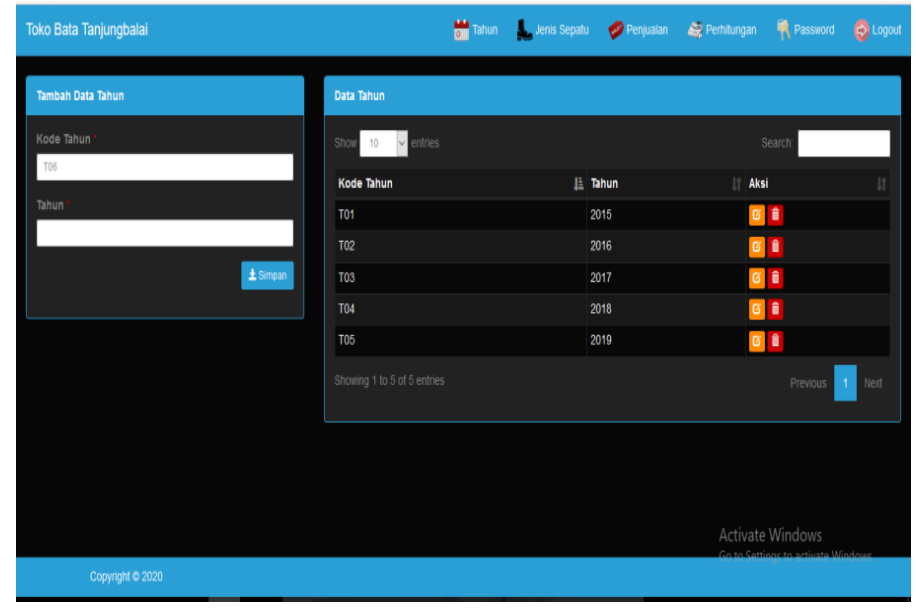

Gambar 2. Tampilan Menu Utama 
Vol. 1 No. 2, Juni 2021, hlm. 161 - 166

DOI: https://doi.org/10.33330/jutsi.v2i1.1163

Available online at http://jurnal.stmikroyal.ac.id/index.php/jutsi

\section{Tampilan Jenis}

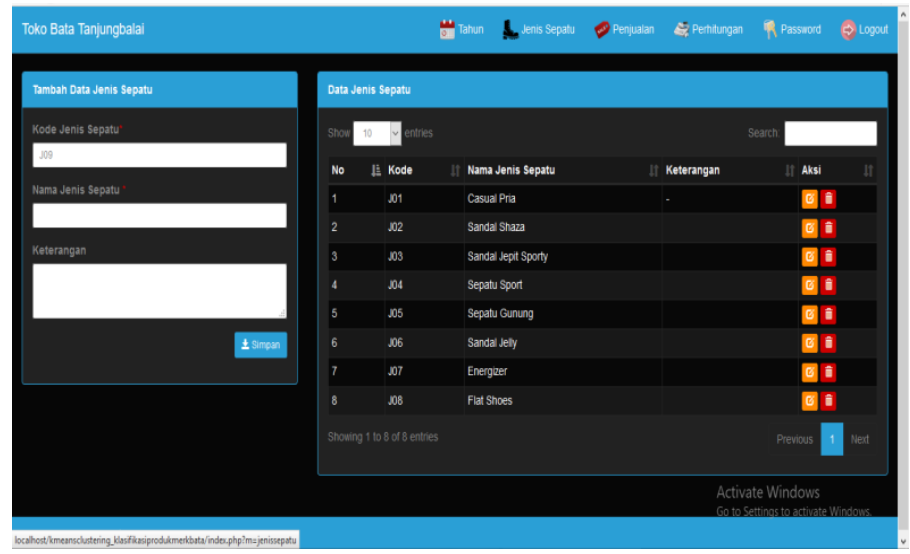

Gambar 3. Tampilan Jenis Sepatu

\section{Tampilan Penjualan}

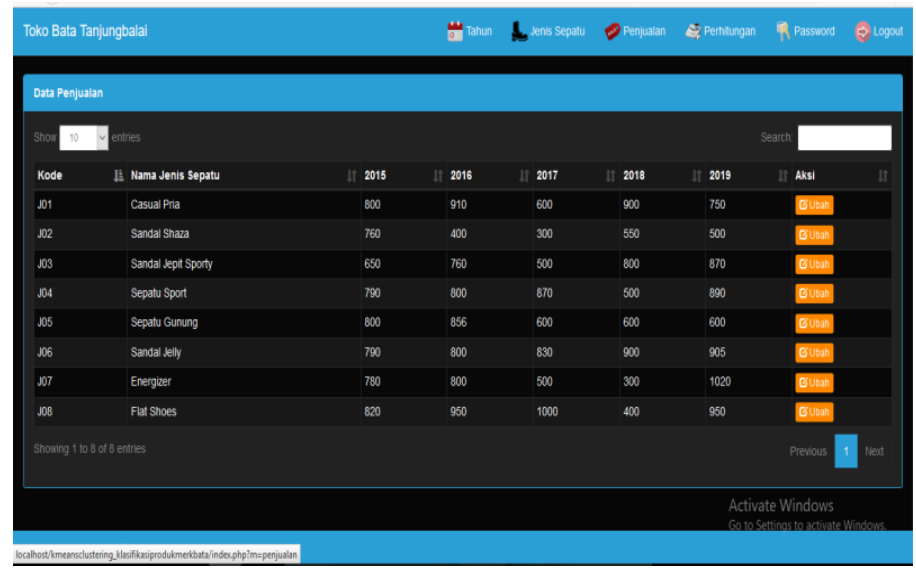

Gambar 4. Tampilan Penjualan

Tampilan Perhitungan

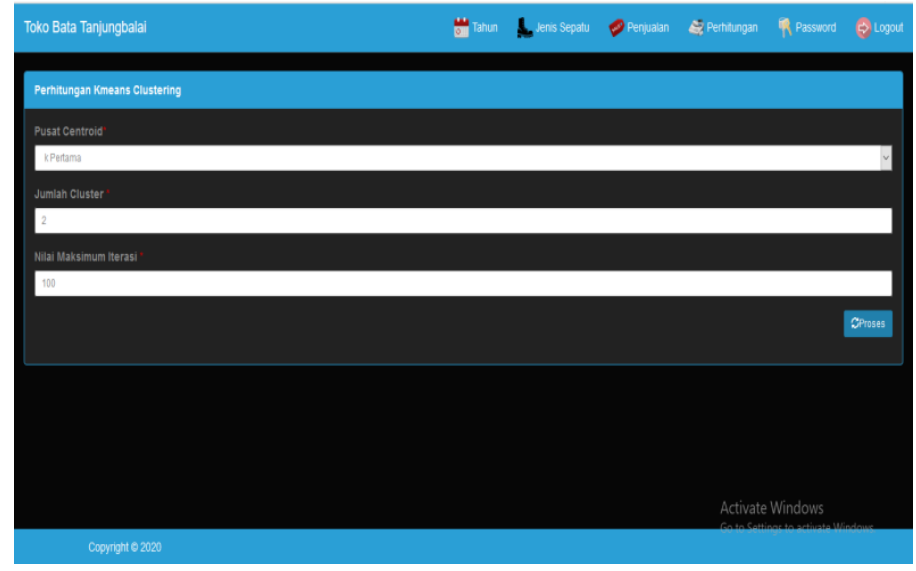

Gambar 5. Tampilan Menu Perhitungan 
Vol. 1 No. 2, Juni 2021, hlm. 161 - 166

DOI: https://doi.org/10.33330/jutsi.v2i1.1163

Available online at http://jurnal.stmikroyal.ac.id/index.php/jutsi

\section{Tampilan Hasil Perhitungan di Grafik}

Gambar di bawah ini menunjukan Hasil Perhitungan Melalui Grafik.

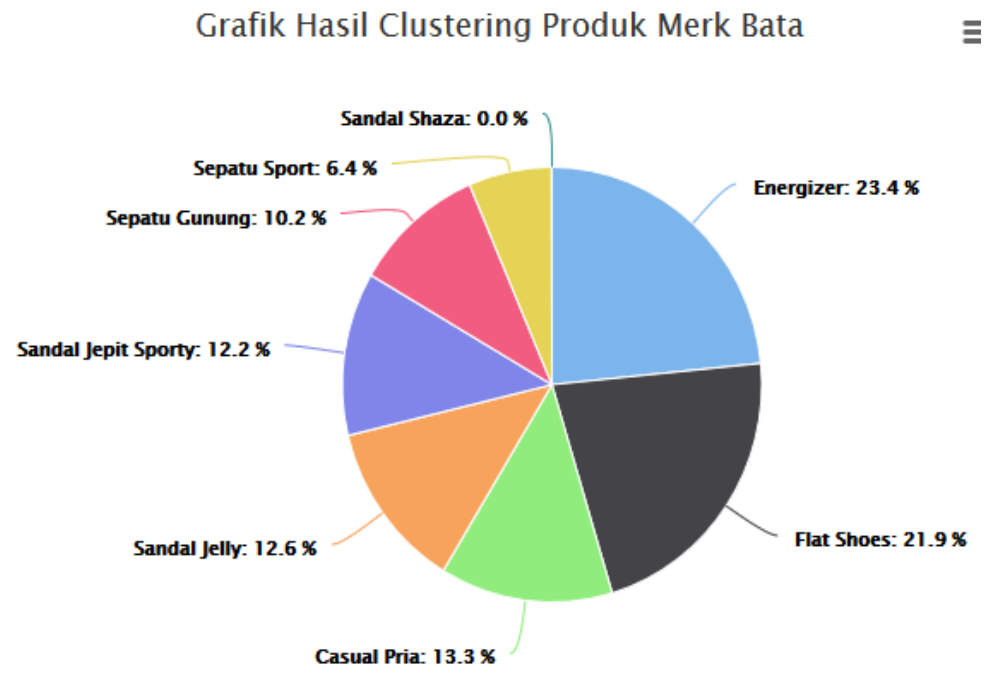

Gambar 6. Tampilan Hasil Akhir dari Menu Perhitungan

\section{SIMPULAN}

Berdasarkan penerapan dan pengujian yang dilakukan selama membuat sistem klasifikasi produk merk bata di Toko Bata Tanjungbalai menggunakan algoritma $K$ Means ditarik beberapa kesimpulan: (1) Dapat menerapkan data mining untuk klasifikasi produk merk bata menggunakan algoritma K-Means di Toko Bata Tanjungbalai yang berbasis web dengan menggunakan bahasa pemrograman PHP dan database $M y S Q L$., (2) Algoritma K-Means mampu menghasilkan keputusan produk yang laris dan tidak laris.

\section{DAFTAR PUSTAKA}

[1] I. T. Amri and S. Santoso, "Penerapan Data Mining Untuk Menganalisa Tingkat Kelarisan Penjualan Aksesoris Mobil Menggunakan Algoritma K-Means," J. VTech (Vision Technol., vol. 1, no. 2, pp. 25-30, 2018, doi: 10.35141/jvt.v1i2.93.

[2] A. Bastian, H. Sujadi, and G. Febrianto, "Penerapan Algoritma K-Means Clustering Analysis Pada Penyakit Menular Manusia (Studi Kasus Kabupaten Majalengka)," no. 1, pp. 26-32.

[3] F. Indriyani and E. Irfiani, "Clustering Data Penjualan pada Toko Perlengkapan Outdoor Menggunakan Metode K-Means," JUITA J. Inform., vol. 7, no. 2, p. 109, 2019, doi: 10.30595/juita.v7i2.5529.

[4] H. Annur, "Penerapan Data Mining Menentukan Strategi Penjualan Variasi 
Vol. 1 No. 2, Juni 2021, hlm. 161 - 166

DOI: https://doi.org/10.33330/jutsi.v2i1.1163

Available online at http://jurnal.stmikroyal.ac.id/index.php/jutsi

Mobil Menggunakan Metode K-Means Clustering," J. Inform. Upgris, vol. 5, no. 1, 2019, doi: 10.26877/jiu.v5i1.3091.

[5] S. Asmiatun and N. Wakhidah, "Identifikasi Pengelompokkan Kondisi Permukaan Jalan Menggunakan Algoritma K-Means," J. Pengemb. Rekayasa dan Teknol., vol. 14, no. 1, p. 17, 2019, doi: 10.26623/jprt.v14i1.1215. 